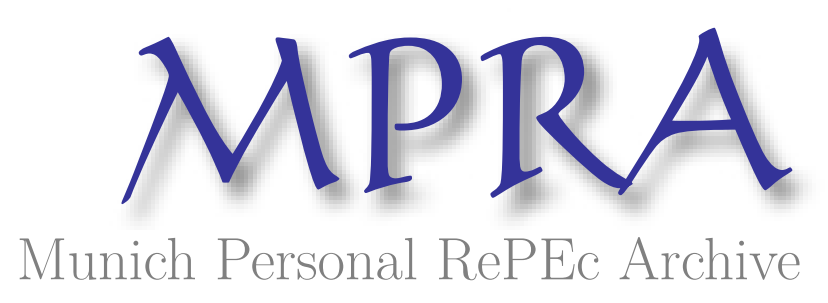

\title{
Methodological Developments in Human Development Literature
}

Nayak, Purusottam

North Eastern Hill University

13 October 2013

Online at https://mpra.ub.uni-muenchen.de/50608/

MPRA Paper No. 50608, posted 14 Oct 2013 08:48 UTC 


\title{
M ethodological Developments in Human Development Literature
}

\author{
Purusottam Nayak
}

\begin{abstract}
The present paper is a review of methodological advancements in human development literature starting from 1990 till date. While highlighting the contribution of UNDP to the concept of human development and construction of HDI it mentions that the introduced concept and method of measurement is a huge qualitative improvement over the earlier concept of growth and per capita GDP measurement. Although the human development report started with a poor methodology, thanks to the galaxy of scholars for their untiring efforts and invaluable contributions in the successive years that enabled UNDP in refining its methodology to a large extent. There is no denying fact that there is no end to refinements, the purpose for which Mahbub ul Haq struggled in his entire life has been served.
\end{abstract}

Introduction: In the early development literature, income per capita was traditionally used to measure development with an assumption that it will directly translate into improved human well being. For decades, the economic growth paradigm dominated the national development discourse. However, in the 1980s unemployment levels escalated. The access to social services deteriorated in many countries including some industrialized nations while at the same time, economic production was expanding. High rates of economic growth did not automatically translate into improved human well-being. During the same period, some countries were registering improvement in human wellbeing with modest economic growth. These raised questions around the nature, distribution and quality of economic growth. People started realizing that while growth-oriented policies may increase a nation's total wealth, whether or not growth enhances human development depends on how that growth is generated and utilized. The economic growth paradigm was, thus, believed to have neglected important aspects of development, such as poverty, income inequalities, unemployment, and disparities in access to public goods and services like health, education, etc and did not capture adequately the multi-dimensionality aspects of development. For economic growth to enhance human development, it should provide an opportunity to enhance workers' knowledge and skills along with opportunities for their efficient use, provide better job opportunities and support greater democracy at all levels of decision-making.

The critique on the use of only the GDP per capita as a proxy of development is dated back to the 1950s. In the past three decades it has been fully recognized that pure economic indicators cannot sufficiently capture the multidimensionality of human development. Many researchers have been 
insisting on the inadequacy of income as the sole indicator of welfare and arguing that income should be supplemented by other attributes of welfare such as health and education. The basic needs approach advocated by development economists regarded development as an improvement in an array of human needs and not just as a growth of income. Sen (1985, 1987 and 1997) defined standard of living in terms of (i) functioning, which indicates attainments of different attributes, and (ii) capability, which is the ability to attain. The capability approach emphasized what a person can do and not what he can purchase as the ultimate metric of wellbeing. An example of a functioning achievement index is the human development index (HDI) conceived by Mahbul ul Haq and introduced by UNDP in its first Human Development Report (HDR, 1990) which ever since has been published annually. HDR is one of the major contributions that reoriented the debate on the measurement of development beyond the traditional economic perspective towards a broader scheme that incorporates different aspects of life into measures of development. The report recognized development to be much more than just the expansion of income and wealth. It defined human development as 'the process of enlarging people's choices' (UNDP, 1990: 10). It also stressed that the choices available to people can be infinite and can change over time. But at all levels of development, the three essential ones are for people to lead a long and healthy life, to acquire knowledge and have command over resources for a decent standard of living. The report made its most distinctive contribution to the larger development discourse by highlighting these dimensions as being basic to human development and in asserting that all the three are essential. Based on this framework, the report constructed the HDI for 130 countries as a measure of its human development along three dimensions: life expectancy at birth as the indicator for a healthy life, adult literacy as the indicator for the knowledge, and common logarithm value of the per capita real GDP as the indicator for the standard of living. HDI was then constructed in three steps. In the first step, a measure of deprivation of a country for each dimension was estimated on a scale between 0 to 1 where 0 corresponds to the minimum, and 1 to the maximum assigned value for the corresponding indicator. Thus, for each component dimension $(i)$ of the HDI, individual Deprivation Indices $(D I)$ for a given country $(j)$ were computed according to the formula as follows:

$$
\text { (1).........................DI } I_{i j}=\frac{\operatorname{Max}\left(X_{i j}\right)-X_{i j}}{\operatorname{Max}\left(X_{i j}\right)-\operatorname{Min}\left(X_{i j}\right)}
$$

In the second step an Average (arithmetic) Deprivation Index (ADI) of three dimensions was determined: 


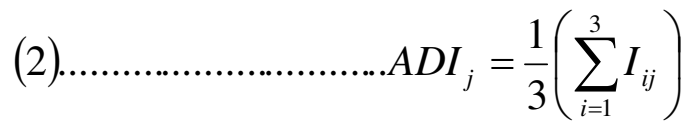

The third stage was the measurement of $H D I$ as one minus the average deprivation index $(A D I)$ : $H D I_{j}=\left(1-A D I_{j}\right)$

For the construction of deprivation indices for different dimensions maximum and minimum values of the variables were determined from the actual values as shown in Table 1:

\begin{tabular}{|l|c|c|}
\hline \multicolumn{3}{|c|}{ Table 1: Dimension Indices } \\
\hline \multirow{2}{*}{ Indicators } & \multicolumn{2}{|c|}{ Scaling Norms for HDI } \\
\cline { 2 - 3 } & Maximum & Minimum \\
\hline Life expectancy at birth (years) & 78.4 & 41.8 \\
\hline Adult literacy rate (per cent) & 100 & 12.3 \\
\hline Real GDP per capita (Log) & 3.68 & 2.34 \\
\hline
\end{tabular}

Although the concept and methodological aspects of human development were visualized and put into practice in the first HDR in 1990, like any other composite index, the HDI has been suffering from a number of limitations (for details see Raworth and Stewart, 2003). Among the major ones the following few are worth mentioning: (i) the number, nature and choice of selected dimension variables and their weights, (ii) choice of goal posts, (iii) lack of concern for distributive justice, (iv) the additive structure (substitutability) of index, (v) lack of theoretical justification of the formula. Besides, data availability has been posing a major challenge to capturing important dimensions such as political freedom, environmental sustainability, and degree of people's self respect. In fact the Human Development Report Office encouraged critiques and research on the HDI to help it fulfill its purpose. There have been a large number of critiques after 1990- many of which have been incorporated into the HDI by UNDP. But the struggle is on for refinements in conceptual and methodological aspects of human development and alternative policy options to create a balance between economic growth and protection of the interest of the poor and marginalized. As a result, there has been a plethora contribution in human development literature, particularly on methodology over the years. The present paper is a humble attempt to compile and document all those important methodological changes and put in one place for a better understanding of the subject. 
Individual Authors' Contributions to M ethodological Refinements: Researches on social indicators and quality of life in the twentieth century have been split along three parallel tracks. Psychologists have been focusing on subjective wellbeing, economists on preferences, and sociologists on objective social indicators (Gasper, 2004; Chan et al., 2004; Bulmer, 1983 as quoted by Collomb, et al., 2012). Since the 1990s, stronger connections have been built between economists and psychologists working on the concept of subjective wellbeing (Sirgy et al., 2006; Kahneman and Krueger, 2006). This line of research remains limited but is growing, especially through interdisciplinary approaches (Costanza et al., 2006; Kingdon and Knight, 2006). While it is true that conventional one-dimensional measure continues to dominate development studies, scholars and policy makers are increasingly interested in multi-dimensional wellbeing (Berenger and VerdierChouchane, 2007; Gasper, 2004). An important element in such measures revolves around the integration of objective and subjective indicators of wellbeing (Hagerty et al., 2001; Cummins, 2005). The present paper, however, is limited to those methodologies that are directly related to construction of HDI only.

Hicks (1997) proposed a method to incorporate a concern for distributional inequalities of income, education, and longevity into the framework of HDI. He constructed Gini coefficients $\left(G_{i}\right)$, for a set of 20 developing countries, measuring inequalities of income, educational attainments, and life-span attainments and combined with data from the HDI to produce an Inequality-Adjusted HDI (IAHDI). To construct IAHDI, three steps were suggested by him:

(1) Construction of indices $\left(I_{i j}\right)$ in the first step for each of the three dimensions using the formula:

$$
I_{i j}=\frac{X_{i j}-\operatorname{Min}\left(X_{i j}\right)}{\operatorname{Max}\left(X_{i j}\right)-\operatorname{Min}\left(X_{i j}\right)}
$$

(2) Construction of inequality-adjusted dimension indices $\left(I A I_{i j}\right)$ in the next step as follows:

$$
I A I_{i j}=I_{i j} * \lambda\left(1-G_{i}\right)
$$

For each dimension $i$, the weight is to be given to inequality-adjustment factor as $\lambda_{i}$.

$$
\text { Presumably, } \forall_{i,}\left(\frac{1}{1-G_{i}}>\lambda_{i}>0\right) \text {. }
$$

(3) Finally, estimation of IAHDI as the arithmetic average of these three indices with weights. 
Although he introduced an inequality adjusted HDI, he was not very happy with the application of Gini coefficient as it is not a perfect indicator of inequality. Construction of inequality measures based on Gini coefficients is not free from conceptual as well as empirical difficulties. According to him inequality of longevity is a difficult concept intuitively.

Sagar and Najam (1998) in their paper evaluated how well HDRs lived up to its own conceptual mandate and assessed the ability of the HDI to further the development debate. They observed that the reports had lost touch with its original vision and the index failed to capture the essence of the world it sought to portray. The index focused almost exclusively on national performance and ranking, but did not pay much attention to development from a global perspective. HDI neglected links to sustainability by failing to investigate the impact on the natural system of the activities that potentially contribute to national income and hence to HDI. They cited the examples of Brazil and Indonesia which improved their HDI by converting natural capital to income in an unsustainable manner. Their concern was about the conceptual implications of the method for folding the three component indices into a single index. They believed that the scheme of arithmetic averaging of the dimensions was counter to the notion of their being essential and, therefore, non-substitutable. Accordingly they proposed the incorporation of three simple modifications for the index as a first step to overcome those shortcomings: (1) Dimensional indices that comprised the HDI need to be multiplied instead of being arithmetically averaged. Such a treatment would, in fact, would be closer to treating each dimension as an 'essential' and non-substitutable component by controlling tradeoffs between them; (2) In estimating the standard-of-living dimension, a logarithmic treatment of GDP across the whole range of global incomes will present a less unrealistic depiction of the availability of options across countries without camouflaging inter-country disparities that are all too real; and (3) For the HDI to capture the sustainability dimension of human development, it will need to incorporate some mechanism for accounting overexploitation of natural resources. While they wholeheartedly agreed with the emphasis of expanding people's options by UNDP, simultaneously cautioned to expand them in a just manner, nationally and internationally and about exercising them wisely. They used the following formulae to construct $H D I$ :

$H D I=\left(\prod_{i=1}^{3} H_{i}\right)^{1 / 3}$ Where $H_{1}, H_{2}, H_{3}$ respectively are education, health and income indices.

Noorbakhsh (1998a) introduced a modified index for measuring human development based on the components of the HDI developed by UNDP. As far as income component is concerned he admitted 
that income beyond poverty-line income $\left(y^{*}\right)$ has no contribution to the HDI as claimed in 1990 report of UNDP. The combination of introducing a cap and taking the logarithm of income was to reflect, rather sharply, the diminishing marginal contribution of income to the human development (UNDP, 1991). Subsequent reports accepted that income above $\left(y^{*}\right)$ will have some effect on the HDI. This modification was to take into consideration the wider people's choice rendered through higher income. This was reflected by using the Atkinson formulation for the utility of income $W(y)$ as:

$W(y)=\left(\frac{1}{1-\varepsilon}\right) y^{1-\varepsilon}$.

Where parameter epsilon $(\varepsilon)$ is the elasticity of marginal utility of income and measures the extent of diminishing returns and reflects the deviation of the elasticity of the utility of income with respect to income from unity. As epsilon tends to zero (i.e., $\varepsilon \rightarrow 0$ ), fractions of income above poverty level will have a more significant effect; and for $\varepsilon=0$, the dollar for dollar effect would be reflected fully. As epsilon tends to one, the above mentioned equation of utility of income is reduced to $W(y)=\log (y)$. Accordingly income above $y^{*}$ was divided into selected intervals. Keeping these points in view and in order to consider further variations in income he divided the income range above $y^{*}$ into more subsets and assumed different values for $\varepsilon$ as shown in Table 2:

\begin{tabular}{|c|l|c|c|c|c|}
\hline \multicolumn{7}{|c|}{ Table 2: Range of Income, $\varepsilon$ and Elasticity } \\
\hline Value of $\varepsilon$ & Range of Income $(\mathbf{y})$ & Elasticity & Value of $\varepsilon$ & Range of Income $(\mathbf{y})$ & Elasticity \\
\hline 0.0 & $y \leq y^{*}$ & 1.0 & 0.5 & $3.0 y^{*}<y \leq 3.5 y^{*}$ & 0.5 \\
\hline 0.1 & $y^{*}<y \leq 1.5 y^{*}$ & 0.9 & 0.6 & $3.5 y^{*}<y \leq 4.0 y^{*}$ & 0.4 \\
\hline 0.2 & $1.5 y^{*}<y \leq 2.0 y^{*}$ & 0.8 & 0.7 & $4.0 y^{*}<y \leq 4.5 y^{*}$ & 0.3 \\
\hline 0.3 & $2.0 y^{*}<y \leq 2.5 y^{*}$ & 0.7 & 0.8 & $4.5 y^{*}<y \leq 5.0 y^{*}$ & 0.2 \\
\hline 0.4 & $2.5 y^{*}<y \leq 3.0 y^{*}$ & 0.6 & - & - & - \\
\hline
\end{tabular}

He further argued that the principle of diminishing returns also applies to educational attainments. Under similar conditions the early units of educational attainments to a country should be of much higher value than the last ones. In the context of policy-making in a country with 30 per cent adult literacy, improvements in literacy are of far greater urgency than the same for a country with 90 per cent adult literacy (Noorbakhsh 1998a: 519). To reflect the diminishing returns he found a set of weights $\left(w=e^{x}\right.$ where $-\infty \leq x=0$, resulting in $\left.0 \leq e^{x}=1\right)$ reflecting the descending value of the 
ascending consecutive fractions of educational indicators. These weights are suitable for re-scaling the $k^{\text {th }}$ consecutive fraction of education indicator $\rho$ for country $i\left(A_{k \rho}\right)$ as follows:

$$
\sum_{k=1}^{K} A_{i k \rho} e^{x} \text { for } \rho=1,2
$$

The formula used to construct the modified human development index $(M H D I)$ is as follows:

$$
\operatorname{MHDI}_{i}=1-\frac{d_{i}}{\bar{d}+2 s_{d}}
$$

Where: $d_{i}$ is the length of the distance vector from the best country; $\bar{d}$ and $s_{d}$ are the mean and standard deviations of distances for all countries from the ideal country; and $d_{i}$ is defined as:

$$
d_{i}=\left(\sum_{j=1}^{3}\left(Z_{i j}-Z_{0 j}\right)^{2}\right)^{1 / 2}
$$

Where: $Z_{0 j}$ is the standardized score on component $j$ for the ideal country.

Noorbakhsh (1998b) compared several different methods such as Arithmetic Mean, Principal Component Analysis (PCA), and Borda method of arriving at a composite index and found the ranks for all the methods to be very similar. This provided a justification for the current HDI specification.

On two grounds, Human Development Report appeared to be confusing to Palazzi and Lauri (1998): one is that of substitutability between dimension indices, and another is of equal weighting. From the theoretical standpoint, the solution to overcome the confusions lies in introducing a concept of balanced and sustainable human development in which the three aspects are not only indispensable but also reciprocally self-reinforcing- A sort of three legged stool in which balance and sustainability depend on the legs being equal in length. They represented their approach graphically by a cloud of country points in three dimensional coordinate axes representing three dimensions of HDI. The $R_{e}$ line starting from the origin and running equidistant from the three axes (i.e., all the points within the cone) represent the balanced and sustainable development (BSD) as shown in Fig.1. The points outside the cone, conversely, represent states of unbalanced, unsustainable development (USD). 


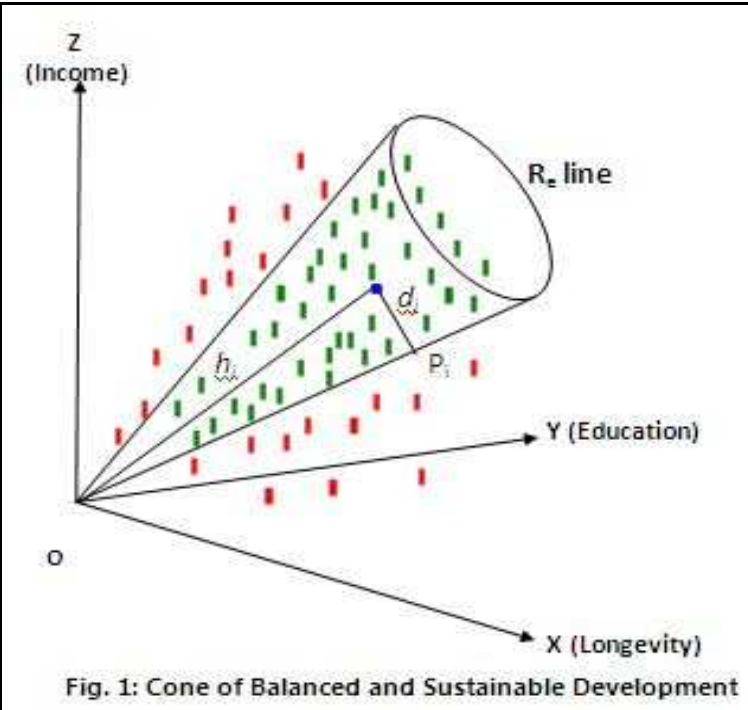

The purpose of defining BSD in the space of sustainability was to devise a mechanism for correcting the values of human development for countries situated outside the area of sustainability. The solution they suggested was to 'penalize' states of human development that fall outside the cone area in proportion to their relative distance from the surface of the cone. To propose an index of BSD, they:

1. First defined a disequilibrium index' $e^{\prime}$, which measures the relative distance of the countrypoint from the objective point on the equilibrium line $R_{e}$ as follows:

$e_{i}=\frac{d_{i}}{h_{i}}$

Where $d_{i}$ indicates the absolute distance of the country-point from the perfect-equilibrium line $R_{e}$ (i.e., the absolute level of country $i^{\prime} s$ disequilibrium) and $h_{i}$ is the distance between the origin and the objective-point along the perfect-equilibrium line (i.e., country $i^{\prime} s$ HDI score). This ratio is equivalent to the tangent of the angle between the perfect equilibrium objective line $R_{e}$ and the line joining the origin to point of the country-point $P_{i}$. The lowest acceptable level of balance and sustainability is designated by them as $e^{*}$.

2. In the second step they estimated the correction coefficient as:

$k_{i}=1-\frac{\hat{E}_{i}^{*}-\hat{E}^{*}}{\max \left(\hat{E}_{i}^{*}\right)-\hat{E}^{*}}=\frac{\max \left(\hat{E}_{i}\right)-\hat{E}^{*}}{\max \left(\hat{E}_{i}^{*}\right)-\hat{E}^{*}}$ 
Where $\hat{E}$ is the between $R_{i}$ (the line joining the origin to $P_{i}$ ); $\hat{E}^{*}$ is the angle of rotation of the cone; and $\max \left(\hat{E}^{*}\right)$ is angle between $R_{e}$ and each of the coordinate axes $\left\{\max \left(\hat{E}_{i}\right)=54.78^{0}\right\}$.

3. In the final step they computed equilibrium-adjusted human development index (EHDI) as:

$E H D I_{i}=k_{i}\left(H D I_{i}\right)$

If $e_{i} \leq e^{*}$ then $k_{i}=1$, and $\mathrm{EHDI}_{i}=H D I_{i}$

If $e_{i}>e^{*}$ then $0 \leq k_{i}<1$, and $\mathrm{EHDI}_{i}<H D I_{i}$

If one the variables is negative, then $k_{i}=0$, and $E H D I_{i}=0$.

The most important conclusion of their work was the recommendation for dropping the assumptions of full substitutability and equal weighting in the construction of the HDI.

Biswas and Caliendo (2001) used the PCA method to arrive at nearly equal weights for the three components: Life Expectancy Index (34\%), Education Index (34\%); GDP Index (32\%) and concluded that:

Despite the simplistic methodology, it appears that the HDI is a good method of combining the component indexes and should be viewed, perhaps, with less skepticism... [L]ittle is lost in the simplistic method, and much is gained in terms of straightforwardness. Indeed, while the strength of the HDI appears to lie in its easy comprehension, the weights used therein are consistent with multivariate techniques that generate weights optimally.

Mahlberg and Obersteiner (2001) made two basic arguments: (a) human development of a country should be benchmarked against best practice countries; and (b) the weights of the component indices should be directly derived from the data. To achieve this, they proposed application of Data Envelopment Analysis (DEA) for computing HDI of different countries. DEA is a leading nonparametric technique for measuring the relative efficiency of decision-making units (DMU) on the basis of multiple inputs and outputs. Any group of entities that receives the same set of inputs and produces the same set of outputs could be designated as a DMU: it could be a group of people, schools, hospitals, companies, industries, and in the present context, it is a group of countries. To determine the relative efficiency of each country in the group, DEA collapses inputs and outputs (human development indicators) into a ratio of a single meta-input and meta-output, and uses methods of linear programming to calculate the efficiency score for each country. The efficiency of a country is the weighted sum of its outputs divided by a weighted sum of its inputs and it is measured on a bounded ratio scale. The weights for inputs and outputs are estimated by a linear 
program in the best advantage for each country so as to maximize its relative efficiency. The highest-ranking country is considered relatively efficient and assigned a perfect score of 1, while the rest of the countries in the sample are considered to be relatively inefficient with scores varying between 0 and 1 . A relatively efficient country cannot improve its levels of output any further while relying on a given level of inputs, while the relatively inefficient countries could. To illustrate the model let us assume that there are $\mathrm{N}$ numbers of DMUs of which one of the DMUs, say the $m^{\text {th }}$ one, whose efficiency is to be maximized is as follows:

$\operatorname{Max}\left(E_{m}\right)=\sum_{j=1}^{J} V_{j m} Y_{j m}$

Subject to : $\sum_{i=1}^{I} U_{i m} X_{i m}=1 \& \sum_{j=1}^{J} V_{j m} Y_{i n}-\sum_{i=1}^{I} U_{i m} X_{i n} \leq 0: n=1,2, K, N$

Where $V_{j m}, U_{i m} \geq 0 ; j=1,2, K, J ; \& i=1,2, K, I$

And $E_{m}$ is the efficiency of the $m^{\text {th }} D M U ; Y_{j m}$ is the $j^{\text {th }}$ output of the $m^{\text {th }} D M U ; V_{j m}$ is the weight of that output; $X_{i m}$ is the $i^{\text {th }}$ input of the $m^{\text {th }} D M U ; U_{i m}$ is the weight of that input; $Y_{j n}$ and $X_{\text {in }}$ are the $j^{\text {th }}$ and $i^{\text {th }}$ inputs respectively of the $D M U, n=1,2, \ldots, N$.

Vega and Urrutia (2001) drew up a framework for pollution-sensitive human development index, which they called as HDPI. The novelty lies in the incorporation into HDI of an environmental factor measured in terms of $\mathrm{CO}_{2}$ emissions from industrial processes. HDPI penalizes those countries which have obtained growth in income at the expense of damaging the environment. The method adopted to construct HDPI is very much similar to that of UNDP method but with few exceptions. They did not bring any change in the formula and variables for the construction of health and education indices. But in case of income index, it was taken as the harmonic average of two indices, namely GDP index and Environment Behavior Index (EBI). The EBI was defined as the difference between unity and $\mathrm{CO}_{2}$ index. The maximum and minimum values (goal posts) were taken as (60, 0 ) tonnes per capita per annum based on global data for 30 years. The HDPI was then constructed for 165 countries as the arithmetic average of three dimension indices such as education index $\left(H_{1}\right)$, health index $\left(H_{2}\right)$, and pollution adjusted GDP index $\left(H_{3} P\right)$ as follows:

$$
H D P I=\frac{1}{3}\left(H_{1}+H_{2}+H_{3} P\right)
$$


where $H_{3} P=\left[\frac{\left(H_{3}\right)^{1-\varepsilon}+(E B I)^{1-\varepsilon}}{2}\right]^{\frac{1}{1-\varepsilon}}$ and $E B I=1-C_{2} I$

To take care of inequality in GDP and pollution, they adopted Atkinson formula where $\varepsilon$ stands for degree of aversion to inequality. When $\varepsilon=0$, there is no penalty and the result is the simple arithmetic average. As $\varepsilon$ grows, pollution-sensitive income decreases and the inequality between the levels of the two indicators is increasingly punished. In their calculation they gave a value of 2 to $\varepsilon$, implying adoption of harmonic mean of GDP and EBI Indices for the construction of pollution adjusted GDP index. However, at the concluding remarks they suggested that the future researchers should make attempts to incorporate other pollutant emissions covering air, water and soil pollution, and other environmental indicators such as deforestation, energy consumption, the exhausting of physical resources, etc.

According to Neumayer (2001) a country's human development is potentially unsustainable if the net depreciation of its manufactured and natural capital (resource) stock is bigger than its investment; and this can be judged from the magnitude of genuine saving (net saving minus depreciation of natural capital) by examining whether it is positive or negative. In order to measure depreciation of the natural resource stock, though there is no universally agreed method, he preferred to use the El Serafy (1991) method. He said that theoretically it is possible to improve literacy and educational enrolment as well as life expectancy with an unsustainable income stream and indeed with falling income levels if only more and more of the income is spent on health and education. But in the long run these cannot be sustainable unless income is sustainable. For this reason he proposed to link the HDI with sustainability of income but not with environment as attempted by many other academicians including Vega and Urrutia (2001). The proposal was based on the line of thinking of HDR (1998) which demanded consumption to be sustainable. Making an analysis for 155 countries he concluded that the indicated human development of 42 countries were potentially unsustainable. Most of these countries had a low HDI, which means that even this low achievement is not sustainable in the future.

Cahill (2002) while supporting the concavity assumption of UNDP stated that achieving a respectable level of human development does not require unlimited income. The essential idea is that increases in income for poor countries add more to human development than increases for wealthy ones. For example, at low income levels, a $\$ 100$ increase in average income may typically buy a higher level of 
nutrition or education, while at high income levels an extra $\$ 100$ may typically buy extra computer memory or snacks. However, some authors were opposed to the concavity assumption (Srinivasan, 1994; Sen, 1981). To settle this issue he made an empirical investigation by estimating the correlation coefficients between income (GDP, the square of GDP and natural logarithm of GDP) and other dimension variables of HDI. The findings revealed that correlation coefficients were largest and statistically significant with logarithm of GDP as compared to GDP and the square of GDP implying the fact that higher levels of GDP are associated with greater levels of development, but at a decreasing rate. This proved concavity assumption and thus justified the application of natural logarithm to GDP for constructing HDI.

Panigrahi and Sivramkrishna (2002) stated that HDI is sensitive to the change of the choice of limits. Any change of maximum and minimum values (goal posts) brought out in any dimension variable not only change absolute values of HDI of different countries but also their rankings. To overcome this problem they proposed to construct an adjusted $\mathrm{HDI}$, called as $A H D I$ through five steps:

Step 1: First construct dimension indices of health, education and income (i.e., LEB, EDN and GDP) of different nations using UNDP method;

Step 2: Define

$l=L_{h}-L_{k}$, where $L_{h}$ is the maximum actual LEB index value, say, is of country $\mathrm{h}$, and $L_{k}$ is the minimum actual LEB index value, say, of country $k$;

$e=E_{m}-E_{n}$, where $E_{m}$ is the maximum actual EDN index value, say, of country $\mathrm{m}$, and $E_{n}$ is the minimum actual EDN index value, say, of country $n$;

$g=G_{p}-G_{q}$, where $G_{p}$ is the maximum actual GDP index value, say, of country p, and $G_{q}$ is the minimum actual GDP index value, say, of country $q$.

Step 3: Choose the minimum of $(l e, g)$. Let us suppose that $l$ is the minimum value among these. Then convert $e$ and $g$ into $e^{*}=\frac{l}{e}$ and $g^{*}=\frac{l}{g}$

Step 4: Since $l$ is found to be minimum, compute adjusted $L_{j}, E_{j}$ and $G_{j}$ as follows: $a L_{j}=L_{j} ; a E_{j}=e^{*} E_{j} ; a G_{j}=g^{*} G_{j}$

Step 5: Finally construct adjusted human development index as: $A H D I=\frac{\left(a L_{j}+a E_{j}+a G_{j}\right)}{3}$ Chakravarty (2003) developed a generalized HDI through an axiomatic approach that satisfies three properties, namely, normalization (NOM), consistency in aggregation (CIA), and symmetry (SYM) 
across attributes. Instead of taking three usual dimensions he proposed estimation of HDI based on 'k' no. of dimensions/ attributes as follows:

$I_{r}=\frac{1}{k} \sum_{i=1}^{k}\left(\frac{x_{i}-m_{i}}{M_{i}-m_{i}}\right)^{r}, 0<r<1$ where $I_{r}$ decreases with $r$.

For $r=1, \quad I_{r}$ becomes $I_{1}=\frac{1}{k} \sum_{i=1}^{k}\left(\frac{x_{i}-m_{i}}{M_{i}-m_{i}}\right)=$ HDI as suggested byUNDP for ' $k$ ' attributes.

The properties of the index are stated as follows:

NOM : For any $z \in[0,1], I(z, \ldots, z)=z$;

CIA : For any $a, b \in[0,1]^{k}, I\left(a_{1}+b_{1}, a_{2}+b_{2}, \ldots, a_{k}+b_{k}\right)=I\left(a_{1}, a_{2}, \ldots, a_{k}\right)+I\left(b_{1}, b_{2}, \ldots, b_{k}\right)$;

$S Y M:$ For all $a \in[0,1]^{k}, I(a)=I(a P)$, where $P$ is any $k X$ permutation matrix.

The above mentioned properties permit us to determine the percentage contributions made by the attributes to overall achievement. These contributions once determined can in turn be used to separate the attributes according to their degrees of sensitivity to wellbeing. The less susceptible attributes would need policy attention to improve their contributions since all quality-of-life attributes should carry approximately equal weights to achieve an ideal standard of living.

A new measure of human development was proposed by Despotis (2004) on the line of Mahlberg and Obersteiner (2001) in a two-phase process. They kept all the assumptions underlying the HDI except that of the equal-weights scheme for the three major indicators. In the first phase, an ideal value of the composite HDI was estimated for each country by a DEA like index-maximizing model. Then in the second stage, a goal programming model was solved to obtain global estimates of human development, based on optimal common weights for the component indicators. They claimed that their new measure of human development is comparable and highly correlated with the HDI. The superiority of the new measure is that the weights assumed for the component indicators, as a result of an optimization process, are less arbitrary and contestable.

Baliamoune-Lutz (2004) proposed a framework to measure HDI and individual components of human well-being (HWB) using fuzzy-set theory in consistence with Sen's Capability Approach. In HWB he included a wide array of seven components: the first three were UNDP's health index, education index, and GDP index, the fourth one was the ICT index, fifth and sixth were the political and civil liberty indices of Freedom House and the last index was based on infant mortality, underfive mortality, access to urban sanitation and improved water source. The results indicate that the 
methodology adopted by UNDP and the Fuzzy Set Theory yielded different rankings of countries in terms of HDI. The same conclusion was equally valid for different component indices of HWB.

Jha and Bhanumurthy (2004) mentioned in their paper that in the pristine natural state there is no entropy, and hence, no degradation or disorganization of the state of the world. Entropy occurs due to unwarranted human activity, be it production or consumption. They supported the view of other scholars that global environmental degradation which has direct bearing on overall human development is not only caused by the factors related to production/income (Grossman \& Krueger, 1992, 1994; Radetzki, 1992; Panayotou, 1997; Grossman, 1995) but also by consumption (Ehrlich and Holdren, 1971). Their basic hypothesis is that excessive and lop-sided consumption patterns are the most fundamental cause of entropy. Therefore, it is important to identify and measure their contribution to global environmental degradation. According to them production-based approaches do not capture the degradation that is caused directly by consumption in terms of vehicular pollution, excessive use of water resources, energy, paper, etc. While consumption is a derivative of income, there is reason to believe that consumption may nonetheless be a better measure than income in relation to the impact on environmental degradation. Thus as an alternative to UNDP's income-based human development index, they developed a consumption-based HDI.

The measurement of human well-being is not only limited to economic indicators but also social, institutional and ecological ones. "As a typical example ... one can cite Prescott-Allen's (2001) human wellbeing index ... and ecosystem well-being index (EWI), integrating two indices with socialeconomical and environmental dimensions" (Zaim, 2005: 1). He also stated that HDI not only fails to measure performance comparisons across time but also dependent on artificially assigned weights. To overcome these limitations he proposed a framework for incorporating environmental indicators to the measurement of human well-being. Furthermore he proposed an improvement index which alleviates the well-known deficiency of across-time comparison of the deprivation index. The advantage of the proposed index is that it does not require normative judgment in the selection of weights to aggregate over constituent indices. Rather, within an activity analysis framework, optimally chosen weights are determined by the data. In developing the index, due emphasis was put on production with negative externalities, and directional distance functions.

Lee et al. (2006) also criticized the arbitrary system of equal weighting of component indices in the construction of HDI. To determine the optimal weights of component indices and to assess the 
relative performance of the countries in human development based on optimal weights they presented a fuzzy multiple-objective DEA model.

Grimm et al. (2008) following the footsteps of Sagar and Najam stated that HDI looks at average achievements only and, thus, does not take into account the distributional aspects of human development within a country. To overcome this they focused on inequality in human development across the income distribution and generated a separate HDI for different segments of income distribution.

Nathan et al. (2008) questioned the linear averaging (LA) method of constructing HDI since it assumes perfect substitutability among indices. They not only questioned the appropriateness of LA method but also proposed a new method which they called it as Displaced Ideal (DI) method. The DI method is based on the concept that the better system should have less distance from ideal. In a three-dimensional HDI space the ideal denotes full attainment on all the three dimensions of health (h), education (e), and income (y) [i.e., $h=e=y=1$ ]. Inverse of the normalized Euclidian distance from the ideal gives the HDI through DI method as follows:

$$
H D I^{D I}=1-\left(\frac{\sqrt{(1-h)^{2}+(1-e)^{2}+(1-y)^{2}}}{\sqrt{3}}\right)
$$

Where $\sqrt{(1-h)^{2}+(1-e)^{2}+(1-y)^{2}}$ is the Euclidian distance from the ideal and when Euclidian distance is divided by $\sqrt{3}$ it gets normalized in the three-dimensional space; further when it gets subtracted from unity gives the inverse which is known as $H D I^{D I}$.

According to Somarriba and Pena (2009) Principal Component Analysis as a method does not allow making cardinal inter-spatial and inter-temporary comparisons but only ordinal comparisons as opposed to DEA. The weights of partial indicators lack socio-economic interpretation. The method has a tendency to pick up the subset of highly correlated variables to make the first component and assign marginal weights to relatively poor correlated subsets of variables. Although DEA facilitates spatial and temporary comparisons and guarantee impartiality in the weights but the program could assign a zero or very low weight to a specific factor. It has the disadvantage of yielding multiple virtual solutions and the existence of restrictions causes problems of non-feasibility. It further allows some degree of arbitrariness in the model while identifying output and input variables. To overcome these deficiencies Pena (1977) proposed a composite synthetic indicator, called as P2 Distance, 
which has been used in the literature to measure quality of life and human development. The formula used to estimate DP2 was:

$D P 2_{i}=\sum_{j=1}^{m}\left[\left(\frac{d_{i j}}{\sigma_{j}}\right)\left(1-R_{j, j-1, \ldots, 1}^{2}\right)\right] ; i=1,2, \ldots, n$

Where: $i=1,2, \ldots, n$ are cases (countries/districts) and $m$ is the number of constituent variables, $X$, such that $x_{i j} \in X ; i=1,2, \ldots, n ; j=1,2, \ldots, m ; d_{i j}=\left|x_{i j}-x_{\rho j}\right| ; i=1,2, \ldots, n ; j=1,2, \ldots, m ; \rho$ is the reference case pertaining to $\min _{i}\left(x_{i j}\right) ; \sigma_{j}$ is the standard deviation of variable $j ; R_{j, j-1, \ldots, 1}^{2} ; j>1$; is the coefficient of determination in the regression of $x_{j}$ over $x_{j-1}, x_{j-2}, \ldots, x_{1}$.

Ray (2008) constructed a Social Development Index (SDI) suitably combining ten physical indicators across 102 countries on the lines of PQL considering development as a multidimensional phenomenon. Since physical indicators chosen for the study were highly correlated, correlation method of obtaining weights was considered by him to be the most suitable one among the host of methods. His findings revealed that correlation method applied on highly correlated variables of SDI yielded near uniform weights. Based on his findings and analysis on the indices of SDI and HDI, he asserted that SDI works better than $\mathrm{HDI}$ as a measure of development for an international comparison.

The additive structure of the index advocated by UNDP entails two substantial drawbacks (Herrero, et al., 2010). One is the kind of trade-offs between functioning it admits, as it assumes full substitutability among them. That implies, for instance, that no matter how bad the health state could be, it can always be compensated by furthering either education or income at a constant rate. The second drawback derives from the sensitivity of the index with respect to the way in which the constituent variables are normalized. It can easily be verified that a change in the parameters chosen to normalize the variables may affect not only the resulting magnitudes of the additive HDI but also the ranking they produce. Keeping these points in view they presented in their paper a multiplicative HDI that exhibits three key advantages over the standard additive HDI. The proposed modified $\mathrm{HDI}$ is a theoretically well founded measure which does not impose the restriction of a constant rate of substitution between the three dimensions of HDI and allows for the introduction of distributive considerations. The method uses geometric mean of the components in place of arithmetic mean as a way of aggregating the three selected indicators, under a suitable theoretical 
justification. They further proposed a new set of variables for the health and education dimensions that are intended to improve the sensitivity of those partial indicators especially for highly developed countries. Life potential (per capita) was proposed in place of life expectancy and expected years of schooling (approach followed by the American Human Development Index) in place of education which puts more weights on literacy. Life potential index is a measure of the average life expectancy of the population, taking into account its demographic structure. The Human Mortality Database that provides both the life tables and the distribution of the population by age for almost all the countries in the OECD was used by them to construct Life Potential Index $(L P I)$ following their suggested formula:

$$
L P I=\frac{1}{N} \sum_{x=0}^{\infty} N_{x} e_{x}
$$

Where: $N_{x}$ is the number of people of age $x, e_{x}$ is the expected number of years that people of that age will live and $N$ is the population size.

Herrero et al. (2012) further stated that the principle of 'decreasing marginal utility' is not only applicable to income but also to health and education. If we think of the HDI more as a welfare measure, it might be reasonable to keep measuring all the three variables in terms of logs. If we rather think of the HDI as an indicator that provides a summary description of the capacity of a country to grow, compete and enhance material wellbeing, as we actually do, the use of logs does not seem justified in any of its variables. Indeed, its use helps conceal the existing differences and has doubtful implications on the substitution rates. Besides, the normalization formula adopted by UNDP keeps the use of goalposts for maximum and minimum values in order to transform the original values into relative gains, by subtracting a minimum value and dividing by the range of the variable. While doing so it makes the whole construction of the HDI dependent on the arbitrary choices of the normalization parameters, in particular, on the minimum values. One can easily manipulate the ranking by changing the minimum values of a dimension variable. The way out for this problem is to convert the variable $(x)$ into $\left(x / x^{*}\right)$ where $x^{*}$ could be any reference value during a period or the maximum value. To bring an improvement over HDI constructed in the 2010 report of UNDP they proposed the following changes in terms of variable, normalization process and aggregation:

$>$ Expected years of schooling should be used instead of a combined variable of education in order to give more weight to the future capacities and to simplify the interpretation of this 
partial indicator; and material well-being to be measured in terms of the egalitarian equivalent per capita GNI (i.e. the amount of income that equally distributed would yield the same social welfare as the current income distribution) without logs, to avoid inconsistencies and undesired side effects, and to take distributional aspects into account in a consistent manner.

All variables should be normalized in terms of shares of some maximum values which would ensure an easy interpretation of the normalized values and, most importantly, would make the resulting ranking of the countries, the marginal rates of substitution, and the pair-wise comparison of relative achievements independent on the normalization parameters.

$>$ Geometric mean should be used to make an average as it is justified on theoretical grounds.

M ajor Refinements undertaken by UNDP: The complete list of changes in the methodology brought out by UNDP after its publication of first HDR in 1990 is presented in Table 3. It is seen that UNDP has been exceptionally receptive to all those criticisms mentioned earlier regarding poor data, incorrect choice of indicators, weighting of dimension variables, choice of goal posts, adjustment of income to inequality correction, and poor specification (Stanton, 2007). On some points, index has been changed significantly in response to its critics. Though the methodology has been modified several times over the years, the main framework has remained substantially unchanged. In particular, the three dimensions such as income, life expectancy, and literacy have not been changed, although the methods of computing these indices have been adjusted. There has also been no change in the assumption of equal weighting of the three dimensions in the construction of HDI. However, the assumption of complete substitutability among the dimension variables was changed in 2010 report. What is worrisome is that the methodology has been quite unstable and changing very frequently leading to difficulties in comparison and interpretation of indices over time. Of course, there is no such problem of comparison across countries and their rankings.

Concluding Remarks: The contribution of UNDP to the concept of human development and construction of $\mathrm{HDI}$ is no doubt a huge qualitative improvement over the earlier concept of growth and per capita GDP measurement. The credit for the report's popularity and also the notoriety goes almost entirely to Mahbul ul Haq (Baru, 1998: 2275). No other report of a United Nations Agency has received as much attention or been as controversial as the HDR. It is Haq's undying faith in human endeavor, sense of purpose, optimism, and conviction which gets reflected in his book (which brings together the works of his entire life) and shaped his ideas into a philosophy leading to 
the evolution of the concept of human development and publication of HDR (Haq, 1995). The human development reports over the years have made its most distinctive contribution to the larger development discourse by highlighting and asserting that education, health and income are basic and essential to human development. In less than two and half decades the HDR has evolved from being merely an annual report into an agenda for action for governments and NGOs and a catalyst for new thinking in development economics. Although the report started with a poor methodology, thanks to the galaxy of scholars for their untiring efforts and invaluable contributions in the successive years that enabled UNDP in refining its methodology to a large extent. There is no denying fact that there is no end to refinements, the purpose for which Haq struggled in his entire life, has been served.

\section{References:}

Anand, S. and Sen, A. (1992) "Human Development Index: Methodology and Measurement", Human Development Report Office Occasional Paper No. 12, New York: UNDP.

Baliamoune-Lutz, M. (2004) "On the Measurement of Human Well-being: Fuzzy Set Theory and Sen's Capability Approach", Research Paper No. 2004/16, World Institute for Development Economics Research, United Nations University.

Baru, S. (1998) "Mahbub ul Haq and Human Development: A Tribute" Economic and Political Weekly, 33(35): 2275-2279.

Berenger, V. and Verdier-Chouchane, A. (2007) "Multidimensional Measures of Well-Being: Standard of Living and Quality of Life across Countries" World Development, 35(7): 1259-1276.

Bulmer, M. (1983) "The Methodology of Early Social Indicator Research: William Fielding Ogburn and Recent Social Trends, 1933", Social Indicators Research, 13(2): 109-130.

Cahill, M.B. (2002) "Diminishing Returns to GDP and the Human Development Index" Applied Economics Letters, 9(13): 885-887.

Chakravarty, S.R. (2003) "A Generalized Human Development Index", Review of Development Economics, 7(1), 99-114.

Chan, A. C. M., Cheng, S.-T., Philipps, D. R., Chi, I. and Ho, S. S. Y. (2004) "Constructing a Quality of Life Scale for Older Chinese People in Hong Kong (HKQOLOCP)" Social Indicators Research, 69(3): 279-301.

Chatterjee, S.K. (2005) "Measurement of Human Development: An Alternative Approach" Journal of Human Development, 6(1): 31-53.

Collomb, J.E Alavalapati, J.R. and Fik, T. (2012) "Building a Multidimensional Wellbeing Index for Rural Populations in Northeastern Namibia" Journal of Human Development and Capabilities, 13(2): 227-246.

Costanza, R., Fisher, B., Ali, S., Beer, C., Bond, L., Boumans, R., et al. (2006) "Quality of Life: An Approach Integrating Opportunities, Human Needs, and Subjective Well-Being" Ecological Economics, 61(2-3): 267-276. 
Cummins, R. (2005) "Moving from A Quality Of Life Concept to A Theory" Journal of Intellectual Disability Research, 49(10): 699-706.

Desai, M. (1991) "Human Development: Concepts and Measurement", European Economic Review, 35 (2\& 3), 350-357.

Desai, M. (1995) "Greening of the HDI?" In McGillivray, A. (ed.) Accounting for Change, The New Economics Foundation, London, pp. 21-36.

Despotis, D.K. (2004) "A Reassessment of the Human Development Index via Data Envelopment Analysis" Journal of the Operational Research Society, 56(8): 969-980.

Doessel, D.P. and Gounder, R. (1991) "International Comparisons of the Standards of Living and the Human Development Index", Discussion Papers in Economics No. 72, Brisbane: Department of Economics, University of Queensland.

Ehrlich and Holdren (1971) "Impact of Population Growth", Science, 171(3197): 1212-1217.

E Serafy, S., (1991) "The Environment as Capital" In Costanza, R. (ed.) Ecological Economics: The Science and Management of Sustainability, New York: Columbia University Press, pp. 168-175.

Foster, J.E., Lopez-Calva, L.F. and Szekely, M. (2005) "Measuring the Distribution of Human Development: Methodology and an Application to Mexico" Journal of Human Development, 6(1): 529.

Gasper, D. (2004) "Conceptualizing Human Needs and Well-being”, Hanse Institute for Advanced Study, Germany: Delmenhorst.

Grimm, M., Harttgen, K., Klasen, S. and Misselhorn, M. (2008) "A Human Development Index by Income Groups", World Development, 36(12): 2527-2546.

Grossman, G.M. (1995) "Pollution and Growth: What do we know?", in I. Goldin and L.A.Winters (eds.), The Economics of Sustainable Development, New York: Cambridge University Press, pp. 1946.

Grossman, G.M. and A. B.Krueger (1992) Environmental Impacts of A North American Free Trade Agreement, New Jersey: Woodrow Wilson School, Princeton.

Grossman, G.M . and A.B. Krueger (1994) "Economic Growth and the Environment", NBER Working Paper \#4634: National Bureau of Economic Research.

Hagerty, M.R., Cummins, R.A., Ferriss, A.L., Land, K, Michalos, A.C., Peterson, M., Sharpe, A., Sirgy, J., and Vogel, J. (2001) "Quality of Life Indexes for National Policy: Review and Agenda for Research" Social Indicators Research, 55(1): 1-96.

Haq, Mahbub ul (1995) Reflections on Human Development, New York: Oxford University Press.

Herrero, C., Martinez, R. and Villar, A. (2010) "Improving the Measurement of Human Development", UNDP: Human Development Research Paper 2010/12.

Herrero, C., Martinez, R. and Villar, A. (2012) "A Newer Human Development Index" Journal of Human Development and Capabilities, 13(2): 247-268.

Hicks (1997) "The Inequality-Adjusted Human Development Index: A Constructive Proposal” World Development, 25(8): 1283-1298.

Hicks, D.A. (1997) "The Inequality-adjusted Human Development Index: A Constructive Proposal", World Development, 28(8): 1283-1298 
Hopkins, M. (1991) "Human Development Revisited: A New UNDP Report", World Development, 19(10): 1469-1473.

Jha and Bhanumurthy (2004) "A Consumption Based Human Development Index and the Global Environmental Kuznets Curve". http://papers.ssrn.com/sol3/papers.cfm ?abstract_id=509243

Kahneman, D. and Krueger, A. B. (2006) "Developments in the Measurement of Subjective Wellbeing" Journal of Economic Perspectives, 20(1): 3-24.

Kelly, A.C. (1991) “The Human Development Index: Handle With Care”, Population Development Review, 17(2), 315-324.

Kingdon, G. G. and Knight, J. (2006) "Subjective Well-Being Poverty vs. Income Poverty and Capabilities Poverty?” Journal of Development Studies, 42(7): 1199-1224.

Lai, Dejian (2000) "Temporal Analysis of Human Development Indicators: Principal Component Approach" Social Indicators Research, 51(3): 331-366.

Lee, Lin and Fang (2006) "A Fuzzy Multiple Objective DEA for the Human Development Index" in B. Gabrys, R.J. Howlett, and L.C. Jain (eds.): KES2006, Part II, LNAI 4252, pp. 922 - 928.

Lind, N.C. (1992) "Some thoughts on the human development index" Social Indicators Research, 27(1): 89-101.

Mahlberg, B. and Obersteiner, M. (2001) "Re-measuring the HDI by Data Envelopment Analysis" International Institute for Applied Systems Analysis (IIASA), Interim Report IR-01-069, Austria: Luxemburg.

McGillivray, M. (1991) "The human Development Index: Yet another Redundant Composite Development Indicator?” World Development, 19(10), 1461-1468.

McGillivray, M. (1992) "Measuring Development: A Statistical Critique of the UNDP's Human Development Index", Working Paper Series No. 135, The Hague: Institute of Social Studies.

Nathan, H.S.K., Mishra, S., and Reddy, B.S. (2008) "An Alternative Approach to Measure HDI" Mumbai, INDIA: Indira Gandhi Institute of Development Research (IGIDR), pp. 1-23.

Neumayer, E. (2001) "The Human Development Index and Sustainability- A Constructive Proposal" Ecological Economics, 39(1): 101-114.

Noorbakhsh, F. (1998a) "A Modified Human Development Index", World Development, 26(3): 517528.

Noorbakhsh, F. (1998b) "The Human Development Indices: Some Technical Issues and Alternative Indices" Journal of International Development, 10(5): 589-605.

Palazzi, P. and Lauri, A. (1998) "The Human Development Index: Suggested Corrections." Banca Nazionale del Lavoro (BNP) Quarterly Review, 51(205): 193-221.

Panayotou, T. (1997) "Demystifying the Environmental Kuznets Curve: Turning a Black Box into a Policy Tool", Environment and Development Economics, 2(4): 465-484.

Panigrahi, R. and Sivramkrishna, S. (2002) "An Adjusted Human Development Index: Robust Country Rankings with Respect to the Choice of Fixed Maximum and Minimum Indicator Values" Journal of Human Development, 3(2): 301-311.

Pena, J.B. (1977) "Problemas de la medición del bienestar y conceptos afines" (Una aplicación al caso español). Madrid: Instituto Nacional de Estadística. 
Prescott-Allen, R. (2001) The Wellbeing of Nations: A Country-by-Country Index of Quality of Life and the Environment. Covel, CA: Island Press.

Pyatt, G. (1991) “Poverty: A Wasted Decade”, European Economic Review, 35(2\& 3), 358-365.

Radetzki, M. (1992) "Economic Growth and the Environment", in P. Low (ed.) International Trade and Environment, Washington D.C.: The World Bank, pp. 121-136.

Ram, R. (1982) "Composite Indices of Physical Quality of Life, Basic Needs fulfillment, and Income: A Principal Component Representation" Journal of Development Economics, 11(2): 227-247.

Rao, V.V.B. (1991) "Human Development Report 1990: Review and Assessment", World Development, 19(10), 1451-1460.

Raworth, K. and Stewar, D. (2003) "Critiques of the Human Development Index" in Fukuda-Parr and Shiva Kumar (eds.) Readings in Human Development, New Delhi: Oxford University Press, pp.140152.

Ray, A.K. (2008) "Measurement of Social Development: An International Comparison" Social Indicators Research, 86(1): 1-46.

Sagar, A.D. and Najam, A. (1998) "The Human Development Index: A Critical Review", Ecological Economics, 25(3): 249-264.

Sen, A.K. (1985) Commodities and Capabilities, Amsterdam: North-Holland.

Sen, A.K. (1987) Standard of Living, Cambridge: Cambridge University Press.

Sen, A.K. (1997) On Economic Inequality, Oxford: Clarendon.

Sirgy, M.J., Michalos, A.C., Ferriss, A.L., Easterlin, R.A., Patrick, D. and Pavot, W. (2006) "The Qualityof-life (QOL) Research Movement: Past, Present, and Future" Social Indicators Research, 76(3): 343466.

Stanton, E.A. (2007) "The Human Development Index: A History" Working Paper Series No. 127, Amherst: Political Economy of Research Institute, University of Massachusetts.

Trabold-NuĖbler, H. (1991) "The Human Development Index: A New Development Indicator?" Intereconomics, 26(5), 236-243.

Vega, M.C.L. De La and Urrutia A.M. (2001) "HDPI: A Framework for Pollution-Sensitive Human Development Indicators" Environment, Development and Sustainability 3(3): 199-215.

Zaim, Osman (2005) "A Framework for Incorporating Environmental Indicators to the Measurement of Human Well-Being", Research Paper No. 2005/05, World Institute for Development Economics Research (WIDER), United Nations University. 